\section{(6) OPEN ACCESS}

${ }^{1}$ Department of Paediatrics, Children's Hospital of Fudan University, Shanghai, China ${ }^{2}$ University Children's Hospital, University of Würzburg, Würzburg, Germany

\section{Correspondence to} Christian P Speer, University Children's Hospital, JosefSchneider-Str. 2, Würzburg 97080, Germany; speer_c@ukw.de

Received 8 May 2014 Revised 2 October 2014 Accepted 4 October 2014 Published Online First 25 November 2014

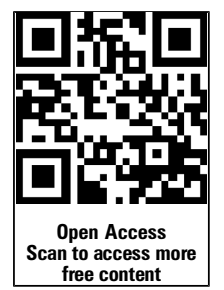

\title{
Late-onset neonatal sepsis: recent developments
}

\author{
Ying Dong, ${ }^{1}$ Christian P Speer ${ }^{2}$
}

\section{ABSTRACT}

The incidence of neonatal late-onset sepsis (LOS) is inversely related to the degree of maturity and varies geographically from $0.61 \%$ to $14.2 \%$ among hospitalised newborns. Epidemiological data on very low birth weight infants shows that the predominant pathogens of neonatal LOS are coagulase-negative staphylococci, followed by Gram-negative bacilli and fungi. Due to the difficulties in a prompt diagnosis of LOS and LOS-associated high risk of mortality and longterm neurodevelopmental sequelae, empirical antibiotic treatment is initiated on suspicion of LOS. However, empirical therapy is often inappropriately used with unnecessary broad-spectrum antibiotics and a prolonged duration of treatment. The increasing number of multidrug-resistant Gram-negative micro-organisms in neonatal intensive care units (NICU) worldwide is a serious concern, which requires thorough and efficient surveillance strategies and appropriate treatment regimens. Immunological strategies for preventing neonatal LOS are not supported by current evidence, and approaches, such as a strict hygiene protocol and the minimisation of invasive procedures in NICUs represent the cornerstone to reduce the burden of neonatal LOS.

\section{INTRODUCTION}

Neonatal sepsis contributes substantially to neonatal morbidity and mortality, and is an ongoing major global public health challenge. ${ }^{1}$ According to the onset of age, neonatal sepsis is divided into early-onset sepsis (EOS) and late-onset sepsis (LOS). EOS reflects transplacental or, more frequently, ascending infections from the maternal genital tract, whereas LOS is associated with the postnatal nosocomial or community environment, with the peak incidence reported to be between the 10th and 22nd day of life. ${ }^{2-5}$ Since the early 1980s, epidemiological studies have observed a general reduction in EOS, probably due to advances in obstetric care and the use of prophylactic intrapartum antibiotics to prevent infections caused by Group B Streptococcus. ${ }^{6}{ }^{7}$ Meanwhile, the incidence of LOS has increased in parallel with the improved survival of premature infants, especially in those with very low birth weight (VLBW), indicating the role of hospitalisation and lifesustaining medical devices in the pathogenesis of neonatal LOS. ${ }^{6} 7$ The microbial characteristics of LOS are of primary importance in guiding clinical antisepsis practice, and strategies to prevent and treat neonatal LOS may, in turn, influence the pattern of LOS pathogens. An up-to-date and thorough understanding of the epidemiology and management of neonatal LOS may help to reduce the burden of this disease.

\section{EPIDEMIOLOGICAL AND CLINICAL ASPECTS OF LOS}

The onset of LOS is most frequently defined at $72 \mathrm{~h}$ after birth, a cut-off time point considered to adequately differentiate LOS from EOS in terms of the spectrum of causative pathogens (table 1). ${ }^{2-5} 7-13$ As demonstrated in table 2, the incidence of LOS is inversely associated with birth weight (BW). Similarly, $36.3 \%$ of neonates with gestational age (GA) <28 weeks had at least one episode of LOS, as compared with $29.6 \%, 17.5 \%$ and $16.5 \%$ of moderately preterm (GA of 29-32 weeks), late preterm (GA of 33-36 weeks) and term infants. ${ }^{4}$ Apart from immaturity, other well-recorded risk factors for LOS include the long-term use of invasive interventions, such as mechanical ventilation and intravascular catheterisation, the failure of early enteral feeding with breast milk, a prolonged duration of parenteral nutrition, hospitalisation, surgery and underlying respiratory and cardiovascular diseases. $^{2} 4111^{13} 14$ It should be noted that genetic factors, such as the polymorphism in immunity-associated genes may also be implicated in neonatal susceptibility to LOS. ${ }^{2}$

Coagulase-negative staphylococci (CONS) have emerged as the predominant pathogens of LOS, accounting for $53.2 \%-77.9 \%$ of LOS in industrialised countries and $35.5 \%-47.4 \%$ in some developing regions (figure 1). ${ }^{2-5}$ 7-13 $\mathrm{In}$ terms of toxin production, CONS are not so virulent as Gram-negative bacteria and fungi, which partly explains the lower rate of short-term infectious complications as well as mortality associated with CONS sepsis. ${ }^{4}$ However, the risk of neurodevelopment sequelae, such as cognitive and psychomotor impairment, cerebral palsy, and vision impairment was independent of the type of pathogen, indicating that CONS are capable to exert a long-term detrimental effect on the host, particularly on the most immature infants with a BW $<1000$ g. $^{15}$ Recent data shows that CONS, predominantly Staphylococcus epidermidis, is highly variable in genetic background and can acquire pathogenic determinants, such as the capability to establish biofilms and antimicrobial resistance in order to become better adapted to the nosocomial environment. ${ }^{16}$ Epidemiological studies in the past decade showed that the most widespread S. epidermidis clone in hospitals is characterised by biofilm-forming capability. ${ }^{16}$ Furthermore, CONS isolates from neonatal intensive care units (NICU) have become increasingly resistant to vancomycin, and strains with antiseptic resistance were also reported. ${ }^{17} 18$

Gram-negative bacilli responsible for neonatal LOS mainly include Escherichia coli, Klebsiella spp., Enterobacter spp. and Pseudomonas spp. (figure 1). Fungi, especially Candida spp., were reported to be one of the major pathogens for LOS 
Table 1 Recent epidemiological data on the incidence of neonatal late-onset sepsis (LOS)

\begin{tabular}{|c|c|c|c|c|c|c|}
\hline Author and country & $\begin{array}{l}\text { No. of } \\
\text { centres }\end{array}$ & $\begin{array}{l}\text { Birth year } \\
\text { of cohort }\end{array}$ & $\begin{array}{l}\text { No. of } \\
\text { neonates }\end{array}$ & $\begin{array}{l}\text { Definition of } \\
\text { the onset of LOS }\end{array}$ & $\begin{array}{l}\text { LOS, } \\
\text { No. (\%) }\end{array}$ & $\begin{array}{l}\text { Proportion (\%) } \\
\text { of CONS }\end{array}$ \\
\hline \multicolumn{7}{|l|}{ VLBW infants } \\
\hline Boghossian et al, ${ }^{2}$ USA & 6 & $2002-2008$ & 15178 & $72 \mathrm{~h}$ & $3797(25.0)$ & 53.2 \\
\hline Lahra et $a l l^{9}$ Australia & 1 & 1992-2004 & 798 & $48 \mathrm{~h}$ & $220(27.6)$ & 64.4 \\
\hline Tröger et al, ${ }^{11}$ Germany & 46 & 2003-2011 & 5886 & $72 \mathrm{~h}$ & $882(15.0)$ & 58.4 \\
\hline \multicolumn{7}{|l|}{ All admitted neonates } \\
\hline Vergnano et $a l_{1}^{3}$ England & 12 & $2006-2008$ & 14225 & $48 \mathrm{~h}$ & $868(6.1)$ & 54 \\
\hline van den Hoogen et al, ${ }^{8}$ Netherland & 1 & 2003-2006 & 2278 & $48 \mathrm{~h}$ & $318(13.9)$ & 77.9 \\
\hline Shim et al, ${ }^{7}$ Korea & 1 & $1996-2005$ & 1479 & $96 \mathrm{~h}$ & $134(9.1)$ & 6.2 \\
\hline Morioka et al, ${ }^{12}$ Japan & 5 & $2006-2008$ & 6894 & $72 \mathrm{~h}$ & $42(0.61)$ & 11.9 \\
\hline Al-Taiar et al, ${ }^{10}$ China (Hebei), Malaysia, Hong Kong and Thailand & 4 & 2006-2009 & 36842 & $72 \mathrm{~h}$ & $782(2.12)$ & 42.2 \\
\hline Tsai et al, ${ }^{4}$ Taiwan & 1 & 2004-2011 & 5010 & 6 days & $713(14.2)$ & 39.9 \\
\hline Hammoud et al, ${ }_{1}^{5}$ Kuwait & 1 & 2005-2009 & 12987 & 6 days & $949(7.3)$ & 35.5 \\
\hline Leal et $a l_{1}^{13}$ Mexico & 1 & 2004-2007 & 11790 & $72 \mathrm{~h}$ & $78(0.66)$ & 47.4 \\
\hline
\end{tabular}

in some regions. ${ }^{7} 13$ The distribution pattern of causative pathogens varies across regions and may change over time within the same hospital due to demographic characteristics of patients, microflora colonisation of the nosocomial environment and the policy of antibiotic use. ${ }^{7}$ It should be noted that application of broad-spectrum antibiotics in the past decades has contributed to an increasing incidence of multidrug-resistant Gram-negative bacilli (MDR GNB), which account for approximately 20\% of bacteraemia cases, and are associated with a 2.8 -fold increase in neonatal mortality rate than are non-MDR strains. ${ }^{19}$

\section{NEW APPROACHES TO DIAGNOSE NEONATAL LOS}

Blood culture remains as the definitive diagnostic tool for neonatal sepsis. However, this 'gold standard' testing method is time-consuming and may produce false positive results as well as false negative results, which can be attributed to the difficulties in discriminating a true CONS infection from sample contamination. $^{20}$ A timely and accurate diagnosis of LOS is of utmost importance, given the mortality rate and long-term adverse outcomes associated with LOS.

The inherent limitations of blood culture technique have given impetus to an extensive search of biomarkers for diagnosing neonatal LOS. ${ }^{20}$ To qualify as an ideal biomarker, many criteria need to be satisfied, such as a small blood volume, high sensitivity and specificity, high positive and negative predicative values, short laboratory turnaround time, 24 hours bedside availability and a reasonable price. Up to now, no single biomarker has been identified to fulfil most, if not all, these criteria. The combination of multiple biomarkers, such as the total

Table 2 Incidence of LOS by birth weight

\begin{tabular}{lllc}
\hline Reference & $\begin{array}{l}\text { Birth weight } \\
(\mathbf{g})\end{array}$ & $\begin{array}{l}\text { No. of } \\
\text { neonates }\end{array}$ & \multicolumn{1}{l}{$\begin{array}{l}\text { LOS, No. } \\
(\%)\end{array}$} \\
\hline Boghossian et al, $^{2}$ USA & $400-500$ & 223 & $146(65.5)$ \\
& $501-750$ & 2680 & $1372(51.2)$ \\
& $751-1000$ & 4030 & $1309(32.5)$ \\
Vergnano et al, $^{3}$ & $1000-1499$ & 1110 & $113(10.2)$ \\
England & $1500-2500$ & 2945 & $66(2.2)$ \\
& $>2500$ & 5340 & $88(1.6)$ \\
\hline LOS, late-onset sepsis. & & &
\end{tabular}

number of neutrophils, immature to total neutrophil ratio and C-reactive protein (CRP) holds promise to enable a fast and accurate diagnosis of LOS. ${ }^{21}$ Sequential detection of CRP may help to rule out microbial infections in a timely manner, facilitating an early cessation of antibiotic treatment. ${ }^{20}$

Recently, molecular-based methods have emerged as promising diagnostic tools for neonatal sepsis. PCR, a technology based on the extraction of microbial DNA from blood samples and the subsequent sequencing or hybridisation of speciesspecific gene regions, is widely investigated for the detection of micro-organisms. ${ }^{22}{ }^{23}$ Furthermore, real-time PCR which focuses on the temporal measurement of fluorescent signals generated in each amplification cycle, has been explored to monitor the microbial load and rapidly target specific micro-organisms in clinical specimens. ${ }^{23}$ Compared with the conventional culture technology, PCR technologies yield results with a higher sensitivity, a much smaller sample volume and less laboratory turnaround time. Recently developed PCR-based diagnostic platforms are highlighted by a low contamination rate, with DNA extraction, multiplex PCR and detection of PCR products performed in a closed system. ${ }^{24}$ This design can help to differentiate potential contamination from true positive cases, particularly for the detection of CONS, since CONS from the patients, nurses taking the blood sample and laboratory personnel may cause contamination. ${ }^{22}$ Another inspiring development in the field of molecular assays is microarray, which is characterised by the hybridisation of clinical samples on a glass or silicon slide preloaded with an array of protein or nucleic acid products. ${ }^{23} 25$ This technology allows us to simultaneously detect pathogens, microbial virulence and even the host immune response profile. $^{23} 25$ Although highly sensitive and specific, microarray cannot replace the conventional method of culture in the isolation of pathogens and the subsequent detection of antibiotic-resistance profile. ${ }^{23}$ The requirement for special instruments and highly trained staff is also one limitation that needs to be addressed. ${ }^{22} 23$

Clinical signs of neonatal LOS are generally regarded as nonspecific and inconspicuous. Recent studies show that monitoring physiological data constantly displayed in neonates is a promising method to predict proven or clinical sepsis. ${ }^{26}$ The greatest advance in this field is the monitoring of heart rate characteristics (HRC), and the rationale is that reduced variability and transient decelerations in heart rate, partly mediated by 
Figure 1 Major causative pathogens of neonatal late-onset sepsis and their incidence by geographical areas.

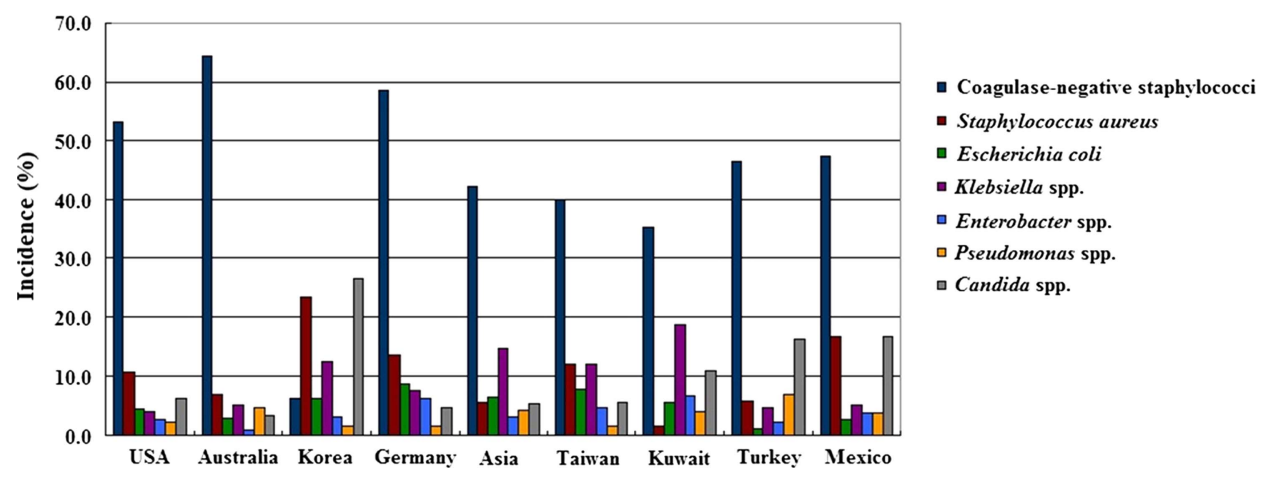

inflammatory cytokines, indicate a high chance of imminent sepsis. ${ }^{26}$ A large randomised trial found a good agreement between expected and proven sepsis by HRC monitoring, and the sepsis-associated mortality was significantly reduced in neonates whose HRC was displayed as compared with the control $(10 \%$ vs $16.1 \%, p=0.01) .{ }^{27}$ Ongoing research combining HRC and other physiological data, such as respiratory rate and blood pressure, may provide more advanced algorithms for an early diagnosis of LOS. ${ }^{26}$

\section{PREVENTION OF NEONATAL LOS}

Given that the treatment of sepsis does not always protect infants from the risk of long-term neurodevelopmental impairments, the best strategy is to prevent rather than to treat LOS. ${ }^{28}$ So far, adherence to infection control protocols remains to be the cornerstone of LOS prevention. By implementing bundles of evidence-based strategies, namely hand hygiene, full-barrier precautions, 2\% chlorhexidine skin antiseptics, avoidance of the femoral route and prompt removal of unnecessary catheters, combined with cultural and behavioural support, the Matching Michigan initiative resulted in a remarkable $47.3 \%$ decrease in the rate of bloodstream infections from central venous catheters in 19 paediatric ICUs in England. ${ }^{29}$ Standardised catheter care bundles used among 24 Ohio NICUs were also shown to be effective by reducing $20 \%$ of LOS. ${ }^{30}$ Because nearly one-third

Table 3 Theoretical mechanisms of currently explored feeding strategies to prevent neonatal LOS

\begin{tabular}{|c|c|}
\hline Explored strategy & Theoretical mechanisms \\
\hline Probiotics $s^{37} 41$ & $\begin{array}{l}\uparrow \text { the intestinal mucosal barrier to prevent the } \\
\text { translocation of bacteria } \\
\text { Competitive exclusion of potential pathogens } \\
\text { Produce bacteriocins that kill pathogens } \\
\uparrow \text { immunoglobulin A mucosal responses } \\
\text { Modulation of host immune reactions to microbial } \\
\text { products } \\
\uparrow \text { enteral nutrition and gut maturation }\end{array}$ \\
\hline $\begin{array}{l}\text { Early enteral trophic } \\
\text { feeding }^{44} 46\end{array}$ & $\begin{array}{l}\text { Prevent the atrophy of gastrointestinal mucosa } \\
\uparrow \text { the establishment of healthy gut microflora } \\
\downarrow \text { the use of parenteral nutrition by facilitating full } \\
\text { enteral feeding } \\
\uparrow \text { gut mucosal immunity }\end{array}$ \\
\hline Lactoferrin ${ }^{28} 38$ & $\begin{array}{l}\text { Antimicrobial effect by iron chelation } \\
\text { Immunomodulatory function through cytokine } \\
\text { production } \\
\uparrow \text { the growth of probiotic bacteria } \\
\uparrow \text { the growth and differentiation of enterocytes } \\
\downarrow \text { the formation of reactive oxygen species }\end{array}$ \\
\hline
\end{tabular}

of LOS were not associated with intravascular catheters, improvement may require other preventive measures, such as the use of prenatal steroids, reduction of assisted mechanical ventilation, early application of continuous positive airway pressure, early surfactant administration and optimal feeding strategies. $^{31}$ Additionally, nationwide surveillance systems can contribute to the reduction of neonatal LOS by providing ongoing surveillance data for quality management and benchmarking between institutions. ${ }^{32}$

Of note, interdisciplinary collaborations at the interface of microbiology and immunology have recently inspired new strategies to prevent neonatal LOS.

\section{Probiotics}

Gut microbiome is the complex and dynamic population of several hundred bacterial species colonising in the gut. It has in delivering nutrients, regulating epithelial maturation and developing innate immune defence against infections. ${ }^{33} 34$ Vaginally delivered term infants are usually colonised by anaerobes, such as Bacteroides spp. and E. coli within days of birth, followed by a predominance of Bifidobacterium spp. and Lactobacilli spp. when breast feeding is initiated. ${ }^{35}$ Caesarean section, prolonged antibiotic use, an extended stay in the healthcare environment and formula feeding can disturb the normal colonisation process. ${ }^{36} \mathrm{VLBW}$ infants were shown to have delayed colonisation of normal bacterial species, as well as less microbial diversity in the intestinal tract due to their frequent exposure to the above-mentioned risk factors. ${ }^{36}{ }^{37}$ An abnormal gut microflora may compromise the integrity of intestinal barrier, causing bacterial translocation into the bloodstream. ${ }^{38}$ CONS were identified to be a predominant species in the stool of VLBW neonates and were closely associated with LOS independent of the presence of indwelling devices, corroborating the role of gut as an important source of potential pathogens causing sepsis. ${ }^{39} 40$ The rationale of using probiotics, therefore, is to normalise the gut microbiome with exogenous microorganisms which commonly comprise Bifidobacterium and Lactobacillus spp. ${ }^{41}$ The potential benefits of probiotics conferred on the host are summarised in table 3. Although theoretically promising, the use of probiotics in clinical trials has revealed inconsistent results with regard to the prevention of nosocomial sepsis, and meta-analyses showed that probiotics did not significantly reduce the incidence of sepsis as compared with the controls. ${ }^{41}{ }^{42}$ The lack of effect may be largely due to the heterogeneity among trials in terms of probiotic administration protocol (strains, dosage, frequency and duration), and more studies are required to determine the efficacy and safety of probiotics in infants. ${ }^{37} 41$ been increasingly recognised as an essential 'organ' of newborns 
Early enteral trophic feeding with breast milk

The initiation of enteral feeding is often delayed in VLBW neonates due to the concern that early enteral feeding may not be tolerated and may be implicated in the pathogenesis of necrotising enterocolitis (NEC). ${ }^{43}{ }^{44}$ However, the lack of enteral feeds may hinder the functional maturation of the gastrointestinal tract, and the prolonged use of parenteral nutrition is associated with an increased risk of systemic infection due to the impairment of immune cell functions. ${ }^{44}$ Trophic feeding, also referred to as minimal enteral feeding and priming feeding, is generally defined as an enteral intake of breast milk and/or formula, with a small volume of up to $24 \mathrm{~mL} / \mathrm{kg} /$ day. ${ }^{43}{ }^{44}$ This strategy attempts to overcome the absence of enteral stimulation while exerting minimal stress on the immature gastrointestinal system. ${ }^{46}$ Early trophic feeding, initiated within the first few days of birth, has shown benefits in the prevention of nosocomial infections without an increased risk of intestinal complications. ${ }^{14} 4647$ Breast milk, apart from its abundant nutrients, also contains secretory antibodies, immune cells, lactoferrin (LF) and prebiotics which can stimulate the growth of beneficial gut flora. $^{33} 48$ Therefore, breast milk has been given priority over formula in the introduction of enteral trophic feeding due to its benefits on the promotion of neonatal immune functions. ${ }^{43} 47 \mathrm{It}$ is demonstrated that human milk feeding started within the first $72 \mathrm{~h}$ after birth was associated with an approximately threefold reduction in the risk of LOS. ${ }^{47}$ Despite numerous studies, multiple factors of the feeding protocol, such as the time of initiation, method of administration and advance rate still remain controversial, and further trials are needed for protocol optimisation. $^{44}$

\section{Lactoferrin}

LF, a major protein in human milk, performs multiple functions as an important component of innate immune defence against infections (table 3). ${ }^{28} 38$ Bovine lactoferrin (BLF) has been shown to significantly decrease the incidence of neonatal LOS as compared with placebo controls. ${ }^{49}$ When combined with probiotics, BLF further enhanced its prophylactic effect on LOS, emphasising the synergistic action of LF and other antimicrobial agents. ${ }^{49}$ However, there was a small number of preterm infants included in these trials, and further studies are warranted to fully assess the effectiveness and safety of LF in neonates by addressing its optimal dosage, duration of treatment and possible combination with probiotics. ${ }^{28}$ The prophylactic use of LF cannot be recommended as routine yet. ${ }^{50}$

\section{Immune replacement therapy}

The immune system of neonates, especially the most immature ones, is characterised by a low neutrophil storage pool and rapid exhaustion of bone marrow reserve during sepsis. ${ }^{23}$ As a consequence, neutropenia may ensue. ${ }^{23}$ Additionally, an inadequate transplacental transport of maternal immunoglobulin $G$ results in a prolonged immunoglobulin deficiency at birth, which is further aggravated during the first month in life. ${ }^{31}$ Based on this knowledge, immune replacement therapies were widely explored in the hope of correcting the immune deficiencies and thus preventing neonatal infections. Colony-stimulating factors (CSF), such as granulocyte CSF and granulocytemacrophage CSF, are cytokines that promote the proliferation and antimicrobial function of neutrophils, monocytes and macrophages. ${ }^{5152}$ However, there was no significant difference in sepsis-free survival between the intervention group and placebo group (table 4). ${ }^{51} 52$ Intravenous immunoglobulins (IVIG), which can enhance opsonic activity, complement activation, antibody-dependent cytotoxicity and neutrophil phagocytosis, showed no prophylactic effect on neonatal sepsis. ${ }^{53}$ It is noteworthy, that IVIG treatment of neonates with suspected or proven sepsis also failed to reduce the mortality in a large multicentre trial. ${ }^{54}$ Moreover, INH-A21, a specific antistaphylococcal immunoglobulins against $S$. epidermidis and Staphylococcus aureus, demonstrated no significant effect to prevent neonates against sepsis despite its theoretical value. ${ }^{55}$

Table 4 Trials for prevention of late-onset sepsis in very low birth weight neonates

\begin{tabular}{|c|c|c|c|c|c|c|}
\hline \multirow[b]{2}{*}{ Trial of example } & \multirow{2}{*}{$\begin{array}{l}\text { Birth year } \\
\text { of cohort }\end{array}$} & \multirow[b]{2}{*}{ Therapy } & \multicolumn{2}{|l|}{ No. of infants } & \multirow[b]{2}{*}{ Outcome } & \multirow[b]{2}{*}{ Results (intervention vs control) } \\
\hline & & & Intervention & Control & & \\
\hline \multicolumn{7}{|c|}{ Immune replacement therapy } \\
\hline Carr et $a F^{52}$ & $2000-2006$ & GM-CSF & 139 & 141 & Sepsis-free survival rate & $\begin{array}{l}66.9 \% \text { vs } 74.5 \% \text {, difference: }-8 \%, 95 \% \mathrm{Cl} \\
-18 \text { to } 3\end{array}$ \\
\hline Kuhn et $\left.a\right|^{51}$ & 2002-2006 & G-CSF & 102 & 98 & Sepsis-free survival rate & $73 \%$ vs $67 \%, p=0.42$ \\
\hline Fanaroff et $a l^{53}$ & 1988-1991 & IVIG & 1204 & 1212 & Incidence of sepsis & $15.5 \%$ vs $17.2 \%, \mathrm{RR}: 0.9,95 \% \mathrm{Cl} 0.75$ to 1.08 \\
\hline DeJonge et $\left.a\right|^{55}$ & $2004-2006$ & INH-A21 & 994 & 989 & Incidence of sepsis & $27 \%$ vs $29 \%, p=0.2$ \\
\hline \multicolumn{7}{|l|}{ Feeding strategies } \\
\hline Jacobs et $\left.a\right|^{42}$ & 2007-2011 & Probiotics* & 548 & 551 & Incidence of sepsis & $13.1 \%$ vs $16.2 \%, p=0.16$ \\
\hline Flidel-Rimon et al 46 & 1995-2001 & Enteral feeding & $385+$ & & $\begin{array}{l}\text { The relationship between the } \\
\text { initiation of feeding and } \\
\text { sepsis }\end{array}$ & $\begin{array}{l}\text { Enteral feeding was started at an earlier age in } \\
\text { infants who did not develop sepsis ( } 2.8 \text { vs } 4.8 \text { days, } \\
p=0.0001 \text { ) }\end{array}$ \\
\hline Manzoni et al ${ }^{49}$ & $2007-2008$ & $\begin{array}{l}\text { BLF alone } \\
\text { BLF plus LGG }\end{array}$ & $\begin{array}{l}153 \\
151\end{array}$ & $\begin{array}{l}168 \\
168\end{array}$ & $\begin{array}{l}\text { Incidence of sepsis } \\
\text { Incidence of sepsis }\end{array}$ & $\begin{array}{l}5.9 \% \text { vs } 17.3 \%, p=0.002 \\
4.6 \% \text { vs } 17.3 \%, p<0.001\end{array}$ \\
\hline \multicolumn{7}{|l|}{ Skin care with antiseptics } \\
\hline Quach et $a 5^{57}$ & 2009-2013 & CHG bathing & $195 \ddagger$ & & Incidence of sepsis & $\begin{array}{l}\text { Sepsis rate decreased in the period of CHG bathing } \\
(6.00 \text { vs } 1.92 / 1000 \text { CVC-days; adjusted RR, } 0.33 \text {, } \\
95 \% \text { Cl } 0.15 \text { to } 0.73 \text { ) }\end{array}$ \\
\hline
\end{tabular}


The failure of immune replacement therapies in the prophylaxis of neonatal sepsis suggests that neonatal immunity is not simply immature, but rather specifically regulated for the early stage of postnatal life, and LOS should be managed based on the immunological specificities of neonates. ${ }^{56}$

\section{Skin care with antiseptics}

Neonates receiving intensive care, especially VLBW infants, are prone to be colonised by pathogenic organisms from the hospital environment. An immature skin barrier and frequent exposure to skin-disrupting procedures further contribute to their vulnerability to nosocomial pathogens. Antiseptics have been shown to reduce skin colonisation of pathogens. ${ }^{57} 58 \mathrm{~A}$ meta-analysis on the use of Chlorhexidine gluconate (CHG), however, yielded no conclusive benefits of $\mathrm{CHG}$ bathing on sepsis prevention (pooled relative risk: 0.65 , 95\% CI 0.40 to 1.05). ${ }^{58}$ It should be noted that there was a high between-trial heterogeneity with regard to $\mathrm{CHG}$ concentration, bathing frequency and patients' baseline characteristics. ${ }^{58}$ Despite a scarcity of reported adverse events, CHG cleansing and bathing is associated with risks of skin irritation and toxic effects following the systemic absorption. ${ }^{59}$ Other concerns are that $\mathrm{CHG}$ may raise skin $\mathrm{pH}$ in infants, thereby disturbing the physiological acidic milieu established on neonates' skin within days of birth. This so-called 'postnatal acid mantle' is important for metabolic activities of keratinocytes and the development of normal skin microflora. ${ }^{60} \mathrm{CHG}$ bathing may remove vernix caseosa, the biological functions of which include mechanical barrier protection and thermoregulation, as well as antimicrobial and immunomodulatory properties. ${ }^{61}$ Furthermore, CHG may eliminate commensal bacteria on the skin and result in a microflora dominated by pathogenic organisms, predisposing the infant to infections. ${ }^{62}$ So far, CHG bathing has not been recommended for routine use in neonates due to a lack of data on safety and efficacy. $^{59}$

\section{ANTIBIOTIC TREATMENT OF LOS}

Due to the potential negative outcomes associated with missed septic cases, empirical antibiotic treatment is initiated on suspicion of LOS. An ideal choice of antimicrobial agents is to cover the most common pathogens without providing selection pressure for antibiotic resistance. ${ }^{63}$ Currently, the recommended first-line therapy is flucloxacillin (or ampicillin) combined with gentamicin. ${ }^{62}$ Recent national surveillance data from UK showed that the vast majority of organisms isolated from LOS blood samples (95\%-97\%) were susceptible to gentamicin+ flucloxacillin and gentamicin + amoxicillin/penicillin, suggesting that the current guideline for empirical therapy is adequate and most LOS cases can be appropriately treated by narrowspectrum antibiotics. ${ }^{64}$ This may hold true for UK and some Western countries. However, in many countries and regions of the world, a different pattern of causative micro-organisms has been identified, and the first-line antibiotic regimen is required to be tailored to the local pathogenic epidemiology. The increasing number of multiresistant strains, especially in developing countries, is a serious matter of concern. As demonstrated by a study of four Asian units, 37\% of all Gram-negative organisms were resistant to gentamicin and approximately one-third were resistant to both gentamicin and third-generation cephalosporins. ${ }^{10}$ Similarly, $14.7 \%$ of all Gram-negative organisms isolated in a hospital in Kuwait were resistant to gentamicin, and a high rate of resistance to cephalosporin $(41.8 \%)$ was observed. ${ }^{5} \mathrm{~A}$ possible explanation is that alternatives to the choice of antibiotics are diverse in these regions and frequently incorporate third-generation cephalosporin, such as cefotaxime, in disregard of the recommended regimens. ${ }^{10} 65$ It is alarming that approximately $20 \%$ of neonatal units in UK and the Republic of Ireland use a cephalosporin, as shown by recent data. ${ }^{65}$ Another concern is the increasingly resistant CONS, and the optimal trough vancomycin concentration has been increased from $5 \mu \mathrm{g}$ / $\mathrm{mL}-10 \mu \mathrm{g} / \mathrm{mL}$ to $10 \mu \mathrm{g} / \mathrm{mL}-15 \mu \mathrm{g} / \mathrm{mL}$ in order to sustain an effective vancomcyin therapeutic range against CONS. ${ }^{63}$ The application of broad-spectrum antibiotics is alerting due to its close association with multidrug-resistance, and it has been reiterated that the spectrum of antibiotics used for empirical therapies should be as narrow as possible.

Apart from the selection of antibiotics, duration of treatment is another important factor to consider in empirical antibiotic therapies. A prompt cessation of antibiotics is generally warranted if blood culture yields negative results after $36-48 \mathrm{~h}$, and the infant shows no subsequent clinical evidence of sepsis or other neonatal infections. ${ }^{63}$ Although appropriately cautious, this practice still leads to unnecessary antibiotic exposure among many infants, since blood cultures are positive in only 5\%-10\% of suspected cases. ${ }^{17}{ }^{21}$ It is alerting that antibiotics are overused in patients who did not actually develop LOS, leading to a higher risk of NEC or death (OR: 2.66, 95\% CI 1.12 to 6.3) among them as compared with patients receiving no or limited antibiotics. ${ }^{67}$ Since the antibiotic treatment of culture-proven sepsis is imperative and unavoidable, minimisation of empirical therapy in infants who have not actually developed sepsis or other neonatal infections contributes substantially to patients' welfare and may help to contain microbial susceptibility to antibiotic treatment.

Given the increasing resistance rate of pathogens and relatively slow development of novel antimicrobial agents, antibiotic stewardship programme (ASP) is designed and implemented to optimise antibiotic therapy. ${ }^{63}{ }^{66} 68$ Major strategies include: ${ }^{63} 6668$ (1) performing prospective audits with interventions and feedbacks; (2) cooperating with local microbiology and infection control staff to regularly monitor the adequacy of antibiotic regimens, because the pattern of causative pathogens and antibiotic resistance profile may change over time and vary geographically; (3) avoiding unnecessary use of broad-spectrum antibiotics in proven infections; (4) reducing antibiotic administration at the start of life and ensuring the cessation of empirical antibiotic treatment when negative blood culture results are obtained; (5) educating antimicrobial prescribers and documenting their compliance with the guidelines. To date, ASPs have shown positive impact on the quality of antibiotic use, with microbiological outcomes improved in $75 \%$ of the studies. ${ }^{68}$

\section{CONCLUSION}

The advance in neonatal intensive care medicine is a doubleedged sword, with improved survival of neonates on one side and an increased rate of LOS on the other. The pathogen pattern of neonatal LOS changes with time and over regions, and should be regularly re-evaluated to guide the management of LOS. Despite all efforts, an early and accurate diagnostic tool for neonatal LOS is yet to be found. In the current empirical antibiotic regimen, ASPs should be implemented to avoid unnecessary usage of broad-spectrum antibiotics and a longer-than-needed duration of treatment. Up to now, the best strategy to treat neonatal LOS lies in prevention. Besides strict adherence to established infection control protocols and less invasive interventions in neonatal intensive care, current evidence shows that early feeding with breast milk is a promising measure to effectively prevent neonatal LOS. 
Contributors YD drafted this manuscript and prepared the tables and figures. CPS revised the manuscript and helped in its editing. Both authors approved the final version.

Competing interests None.

Patient consent Obtained.

Provenance and peer review Commissioned; externally peer reviewed.

Open Access This is an Open Access article distributed in accordance with the Creative Commons Attribution Non Commercial (CC BY-NC 4.0) license, which permits others to distribute, remix, adapt, build upon this work non-commercially, and license their derivative works on different terms, provided the original work is properly cited and the use is non-commercial. See: http://creativecommons.org/ licenses/by-nc/4.0/

\section{REFERENCES}

1 Qazi SA, Stoll BJ. Neonatal sepsis: a major global public health challenge. Pediatr Infect Dis J 2009;28:S1-2.

2 Boghossian NS, Page GP, Bell EF, et al. Late-onset sepsis in very low birth weight infants from singleton and multiple-gestation births. J Pediatr 2013:162:1120-4.

3 Vergnano S, Menson E, Kennea N, et al. Neonatal infections in England: the NeonIN surveillance network. Arch Dis Child Fetal Neonatal Ed 2011;96:F9-14.

4 Tsai MH, Hsu JF, Chu SM, et al. Incidence, clinical characteristics, and risk factors for adverse outcome in neonates with late onset sepsis. Pediatr Infect Dis J 2014;33:e7-13.

5 Hammoud MS, Al-Taiar A, Thalib L, et al. Incidence, aetiology and resistance of late-onset neonatal sepsis: a five-year prospective study. J Paediatr Child Health 2012;48:604-9.

6 Bizzarro MJ, Raskind C, Baltimore RS, et al. Seventy-five years of neonatal sepsis at Yale: 1928-2003. Pediatrics 2005;116:595-602.

7 Shim GH, Kim SD, Kim HS, et al. Trends in epidemiology of neonatal sepsis in a tertiary center in Korea: a 26-year longitudinal analysis, 1980-2005. J Korean Med Sci 2011;26:284-9.

8 van den Hoogen A, Gerards LJ, Verboon-Maciolek MA, et al. Long-term trends in the epidemiology of neonatal sepsis and antibiotic susceptibility of causative agents. Neonatology 2010;97:22-8.

9 Lahra MM, Beeby PJ, Jeffery HE. Intrauterine inflammation, neonatal sepsis, and chronic lung disease: a 13-year hospital cohort study. Pediatrics 2009;123:1314-19.

10 Al-Taiar A, Hammoud MS, Cuiqing L, et al. Neonatal infections in China, Malaysia, Hong Kong and Thailand. Arch Dis Child Fetal Neonatal Ed 2013;98:F249-55.

11 Tröger B, Göpel W, Faust K, et al. Risk for late-onset blood-culture proven sepsis in very-low-birth weight infants born small for gestational age: a large multicenter study from the German Neonatal Network. Pediatr Infect Dis J 2014;33:238-43.

12 Morioka I, Morikawa S, Miwa A, et al. Culture-proven neonatal sepsis in Japanese neonatal care units in 2006-2008. Neonatology 2012;102:75-80.

13 Leal YA, Álvarez-Nemegyei J, Velázquez JR, et al. Risk factors and prognosis for neonatal sepsis in southeastern Mexico: analysis of a four-year historic cohort follow-up. BMC Pregnancy Childbirth 2012;12:48.

14 Stoll BJ, Hansen N, Fanaroff AA, et al. Late-onset sepsis in very low birth weight neonates: the experience of the NICHD Neonatal Research Network. Pediatrics 2002;110:285-91.

15 Stoll BJ, Hansen NI, Adams-Chapman I, et al. Neurodevelopmental and growth impairment among extremely low-birth-weight infants with neonatal infection. JAMA 2004;292:2357-65.

16 Dong Y, Speer CP. The role of Staphylococcus epidermidis in neonatal sepsis: guarding angel or pathogenic devil? Int J Med Microbiol 2014;304:513-20.

17 Rasigade JP, Raulin O, Picaud JC, et al. Methicillin-resistant Staphylococcus capitis with reduced vancomycin susceptibility causes late-onset sepsis in intensive care neonates. PLOS ONE 2012:7:e31548.

18 Lepainteur M, Royer G, Bourrel AS, et al. Prevalence of resistance to antiseptics and mupirocin among invasive coagulase-negative staphylococci from very preterm neonates in NICU: the creeping threat? J Hosp Infect 2013;83:333-6.

19 Tsai MH, Chu SM, Hsu JF, et al. Risk factors and outcomes for multidrug- resistant Gram-negative bacteremia in the NICU. Pediatrics 2014;133:e322-9.

20 Meem M, Modak JK, Mortuza R, et al. Biomarkers for diagnosis of neonatal infections: A systematic analysis of their potential as a point-of-care diagnostics. J Glob Health 2011;1:201-9.

$21 \mathrm{Ng}$ PC, Lam HS. Biomarkers in neonatology: the next generation of tests. Neonatology 2012;102:145-51.

22 Kasper DC, Altiok I, Mechtler TP, et al. Molecular detection of late-onset neonatal sepsis in premature infants using small blood volumes: proof-of-concept. Neonatology 2013;103:268-73.

23 Edmond K, Zaidi A. New approaches to preventing, diagnosing, and treating neonatal sepsis. PLoS Med 2010;7:e1000213.
24 Altun 0, Almuhayawi M, Ullberg M, et al. Clinical evaluation of the FilmArray blood culture identification panel in identification of bacteria and yeasts from positive blood culture bottles. J Clin Microbiol 2013;51:4130-6.

25 Cernada $M$, Serna E, Bauerl C, et al. Genome-wide expression in profiles in very low birth weight infants with neonatal sepsis. Pediatrics 2014;133:e1203-11.

26 Fairchild KD. Predictive monitoring for early detection of sepsis in neonatal ICU patients. Curr Opin Pediatr 2013;25:172-9.

27 Moorman JR, Carlo WA, Kattwinkel J, et al. Mortality reduction by heart rate characteristic monitoring in very low birth weight neonates: a randomized trial. J Pediatr 2011;159:900-6.

28 Manzoni P, Mostert M, Stronati M. Lactoferrin for prevention of neonatal infections. Curr Opin Infect Dis 2011;24:177-82.

29 Bion J, Richardson A, Hibbert P, et al. 'Matching Michigan': a 2-year stepped interventional programme to minimise central venous catheter-blood stream infections in intensive care units in England. BMJ Qual Saf 2013;22:110-23.

30 Kaplan HC, Lannon C, Walsh MC, et al. Ohio statewide quality-improvement collaborative to reduce late-onset sepsis in preterm infants. Pediatrics 2011;127:427-35.

31 Bersani I, Speer CP. Nosocomial sepsis in neonatal intensive care: inevitable or preventable? Z Geburtshilfe Neonatol 2012;216:186-90.

32 Gastmeier P, Sohr D, Schwab F, et al. Ten years of KISS: the most important requirements for success. J Hosp Infect 2008:70(Suppl 1):11-16.

33 Tourneur E, Chassin C. Neonatal immune adaptation of the gut and its role during infections. Clin Dev Immunol 2013;2013:270301.

34 Eckburg PB, Bik EM, Bernstein CN, et al. Diversity of the human intestinal microbial flora. Science 2005;308:1635-8.

35 Fanaro $S$, Chierici R, Guerrini $P$, et al. Intestinal microflora in early infancy: composition and development. Acta Paediatr 2003:91:48-55.

36 Madan JC, Salari RC, Saxena D, et al. Gut microbial colonisation in premature neonates predicts neonatal sepsis. Arch Dis Child Fetal Neonatal Ed 2012:97: F456-62.

37 Garland SM, Tobin JM, Pirotta M, et al. The ProPrems trial: investigating the effects of probiotics on late onset sepsis in very preterm infants. BMC Infect Dis 2011;11:210.

38 Sherman MP. New concepts of microbial translocation in the neonatal intestine: mechanisms and prevention. Clin Perinatol 2010;37:565-79.

39 Gewolb IH, Schwalbe RS, Taciak VL, et al. Stool microflora in extremely low birth weight infants. Arch Dis Child 1999;80:F167-73.

40 Stewart CJ, Marrs EC, Magorrian S, et al. The preterm gut microbiota: changes associated with necrotizing enterocolitis and infection. Acta Paediatr 2012;101:1121-7.

41 Nair V, Soraisham AS. Probiotics and prebiotics: role in prevention of nosocomial sepsis in preterm infants. Int J Pediatr 2013;2013:874726

42 Jacobs SE, Tobin JM, Opie GF, et al. Probiotic effects on late-onset sepsis in very preterm infants: a randomized controlled trial. Pediatrics 2013;132:1055-62.

43 Hay WW Jr. Strategies for feeding the preterm infant. Neonatology 2008;94:245-54

44 Morgan J, Bombell S, McGuire W. Early trophic feeding versus enteral fasting for very preterm or very low birth weight infants. Cochrane Database Syst Rev 2013;3: CD000504.

45 Sweeney B, Puri P, Reen DJ. Induction and modulation of apoptosis in neonatal monocytes by polyunsaturated fatty acids. J Pediatr Surg 2007;42:620-8

46 Flidel-Rimon O, Friedman S, Lev E, et al. Early enteral feeding and nosocomial sepsis in very low birthweight infants. Arch Dis Child Fetal Neonatal Ed 2004;89: F289-92.

47 Rønnestad A, Abrahamsen TG, Medbø S, et al. Late-onset septicemia in a Norwegian national cohort of extremely premature infants receiving very early full human milk feeding. Pediatrics 2005;115:e269-76.

48 Newburg DS, Walker WA. Protection of the neonate by the innate immune system of developing gut and of human milk. Pediatr Res 2007:61:2-8.

49 Manzoni P, Rinaldi M, Cattani S, et al. Bovine lactoferrin supplementation for prevention of late-onset sepsis in very low-birth-weight neonates: a randomized trial. JAMA 2009:302:1421-8.

50 Pammi M, Abrams SA. Oral lactoferrin for the prevention of sepsis and necrotizing enterocolitis in preterm infants. Cochrane Database Syst Rev 2011;(10):CD007137.

51 Kuhn P, Messer J, Paupe A, et al. A multicenter, randomized placebo-controlled trial of prophylactic recombinant granulocyte-colony stimulating factor in preterm neonates with neutropenia. J Pediatr 2009;155:324-30.

52 Carr R, Brocklehurst $\mathrm{P}$, Doré $\mathrm{CJ}$, et al. Granulocyte-macrophage colony stimulating factor administered as prophylaxis for reduction of sepsis in extremely preterm, small for gestational age neonates (the PROGRAMS trial): single-blind, multicentre randomized controlled trial. Lancet 2009;373:226-33.

53 Fanaroff $\mathrm{AA}$, Korones $\mathrm{SB}$, Wright $\mathrm{LL}$, et al. A controlled trial of intravenous immune globulin to reduce nosocomial infections in very-low-birth-weight infants. National Institute of Child Health and Human Development Neonatal Research Network. N Engl J Med 1994;330:1107-13.

54 Brocklehurst P, Farrell B, King A, et al; INIS Collaborative Group. Treatment of neonatal sepsis with intravenous immune globulin. $N$ Engl J Med 2011;365:1201-11. 
55 Dejonge M, Burchfield D, Bloom B, et al. Clinical trial of safety and efficacy of INH-A21 for the prevention of nosocomial staphylococcal bloodstream infection in premature infants. J Pediatr 2007;151:260-5.

56 Levy 0 , Wynn JL. A prime time for trained immunity: innate immune memory in newborns and infants. Neonatology 2014;105:136-41.

57 Quach C, Milstone AM, Perpête C, et al. Chlorhexidine Bathing in a Tertiary Care Neonatal Intensive Care Unit: Impact on Central Line-Associated Bloodstream Infections. Infect Control Hosp Epidemiol 2014;35:158-63.

58 Sankar MJ, Paul VK. Efficacy and safety of whole body skin cleansing with chlorhexidine in neonates - a systemic review. Pediatr Infect Dis J 2013;32: e227-34.

59 Ponnusamy V, Venkatesh V, Clarke P. Skin antisepsis in the neonate: what should we use? Curr Opin Infect Dis 2014;27:244-50.

60 Ness MJ, Davis DM, Carey WA. Neonatal skin care: a concise review. Int I Dermatol 2013:52:14-22.

61 Tollin M, Jagerbrink T, Haraldsson A, et al. Proteome analysis of vernix caseosa. Pediatr Res 2006;20:430-4.
62 Cogen AL, Nizet V, Gallo RL. Skin microbiota: a source of disease or defence? Br J Dermatol 2008;158:442-55.

63 Russell AB, Sharland M, Heath PT. Improving antibiotic prescribing in neonatal units: time to act. Arch Dis Child Fetal Neonatal Ed 2012;97:F141-6.

64 Muller-Pebody B, Johnson AP, Heath PT, et al. Empirical treatment of neonatal sepsis: are the current guidelines adequate? Arch Dis Child Fetal Neonatal Ed 2011;96:F4-8.

65 Fernando AM, Heath PT, Menson EN. Antimicrobial policies in the neonatal units of the United Kingdom and Republic of Ireland. J Antimicrob Chemother 2008;61:743-5.

66 Anthony M, Bedford-Russell A, Cooper T, et al. Managing and preventing outbreaks of Gram-negative infections in UK neonatal units. Arch Dis Child Fetal Neonatal Ed 2013:98:F549-53.

67 Kuppala VS, Meinzen-Derr J, Morrow AL, et al. Prolonged initial empirical antibiotic treatment is associated with adverse outcomes in premature infants. J Pediatr 2011;159:720-5.

68 Lesprit P, Brun-Buisson C. Hospital antibiotic stewardship. Curr Opin Infect Dis 2008;21:344-9. 